\title{
A MODALIDADE DE EDUCAÇÃO A DISTÂNCIA (SEM DISTÂNCIA) NA UNISINOS: UM NOVO CONCEITO PARA INOVAÇÃO?
}

\author{
(DISTANCE EDUCATION AT UNISINOS (BLENDED LEARNING): A NEW IDEA FOR \\ INNOVATION?)
}

\author{
Eliane Schlemmer \\ Susane Garrido \\ Paula Caleffi \\ Universidad Do Vale Do Rio Dos Sinos (Brasil)
}

\section{RESUMEN}

Esse artigo apresenta um breve relato sobre a Educação à distância no contexto da Universidade do Vale do Rio dos Sinos - UNISINOS e discute o conceito de inovação no âmbito do paradigma da complexidade, na Sociedade em Rede ao analisar as transformações sociais e as novas formas de pensamento oriundas das mudanças dos meios tecnológicos. Assim, faz um convite à reflexão sobre o que constitui inovação nos processos de ensino e de aprendizagem, na gestão e na estrutura organizacional, estabelecendo relação com o uso de Tecnologias Digitais -TDs. Problematiza o imaginário que surge em torno das TDs enquanto sinônimo de inovação, evidenciando que por si só elas não se constituem em inovações, na medida em que a inovação implica no rompimento de paradigmas surgindo no conhecer, portanto no viver e conviver.

Palavras chave: educação a distância, comunidades virtuais de aprendizagem, inovação, tecnologias digitais, processos de ensino e de aprendizagem.

\section{ABSTRACT}

This article presents a short narration about On Line Education at UNISINOS University (Universidade do Vale do Rio dos Sinos) context and it discusses the concept of innovation in the ambit of Web Society when analysis the social transformations and the new ways of thinking resultant from changes of the technology field. So that, it invites to a reflection about what is innovation in the teaching 
and learning processes, in the management and in the organizational structure, establishing a relation between the use of Digital Technologies -DTs. It problemizes the imaginary that emerges around DTs while a synonym of innovation, evidencing that alone they are not innovations, as innovation implies in the breaking of paradigms emerging in the knowledge, so in the living and cohabiting.

Key words: distance education, virtual learning environment, innovation, digital technologies, teaching and learning processes.

Os desafios e as mudanças que as organizações humanas vem experimentando estão no foco das discussões da atualidade. Esse tempo de instabilidade se configura em momento propício para inovação, pois nos desloca das nossas zonas de conforto nos levando a descobrir e a criar formas de nos movimentarmos nesse terreno movediço, que caracteriza esse mundo de incertezas, e a enfrentar as turbulências decorrentes de um mundo que muda e se transforma continuamente numa velocidade atordoante. Isso tem tornando antigas práticas, fundamentadas em teorias tradicionais, insuficientes frente a um ambiente altamente complexo e dinâmico impulsionado pela instantaneidade das redes eletrônicas de informação e de comunicação.

De um lado presenciamos uma quantidade e velocidade de mudança sem precedentes na história da humanidade, de outro, organizações que se mostram incapazes de lidar com essas mudanças.

No âmbito das organizações presenciamos a impossibilidade de que estruturas hierárquicas, estruturas verticais e outras formas já conhecidas, respondam a dinamicidade e a complexidade impostas pela sociedade atual, impregnada pela lógica de redes. A teia ou rede é permeada pela flexibilidade, o que possibilita o trabalho por projetos, de forma que para solucionar um determinado problema, é capaz de rapidamente arregimentar pessoas, as quais se agregam em função desse objetivo e interesse específico, desagregando-se ao tê-lo concluído. Posteriormente, ess1as pessoas poderão se reagrupar em configurações diferenciadas, dependendo do tipo de projeto a ser desenvolvido. Dessa forma, uma organização se constitui como uma comunidade que possibilita a criação de micro-comunidades, ou seja, de sub-sistemas que se inter-relacionam e são interdependentes, formando um sistema no qual o todo é maior que a soma das partes, isso significa dizer que se constitui pela soma das partes mais as relações entre elas. A capacidade de sinergia é o que define a especificidade de um meio de inovação, ou seja, o valor agregado resultante não dos efeitos cumulativos dos elementos presentes no meio, mas de sua interação. 
No âmbito dos processos de ensino e de aprendizagem, presenciamos o surgimento de um novo sujeito da aprendizagem, o nativo digital ${ }^{1}$, pelo fato de ter nascido nesse mundo altamente tecnologizado, em rede, dinâmico, rico em possibilidades de informação e comunicação. É evidente para quem convive com crianças e adolescentes - os nativos digitais - perceber a forma diferenciada com que se comunicam e se relacionam com a informação. Eles têm outra forma de ser e estar no mundo, de conviver com as Tecnologias Digitais - TDs, fazendo emergir o que Castells (1999) denomina de cultura da virtualidade real ${ }^{2}$.

É importante salientar que os sistemas educativos encontram-se, atualmente, em crise e submetidos a novas restrições: de quantidade, diversidade e velocidade de evolução dos saberes. A demanda por formação é maior do que nunca. Porém, além do enorme crescimento quantitativo, ela sofre também uma profunda mutação qualitativa no sentido de uma necessidade cada vez maior de diversificação e de personalização. "Os indivíduos toleram cada vez menos seguir cursos uniformes ou rígidos que não correspondem as suas necessidades reais e à especificidade de seu trajeto de vida". (Lévy, 1999 p. 169). Assim, como podemos pensar numa solução para essa crescente demanda, sem cairmos numa massificação da oferta, o que seria de acordo com Lévy (1999), uma resposta industrialista ao modo antigo, inadaptada à flexibilidade e à diversidade necessárias de agora em diante? Como podemos desenvolver ambientes de aprendizagem que atendam essas demandas de uma forma mais personalizada, ou seja, que realmente correspondam às necessidades das pessoas em busca de formação?

As universidades, cada vez mais, oferecem aos estudantes acesso às tecnologias de informação e comunicação: Internet, ambientes educacionais na Web, videoconferência e teleconferência, suportes hipermídia (CD-ROM, bancos de dados multimídia interativos online), sistemas de simulação etc. Torna-se cada vez menos pertinente fazer uma distinção entre educação presencial e educação a distância, pois o uso das redes de telecomunicação e dos suportes multimídia interativos estão sendo integrados dando outra dimensão aos processos de ensino e de aprendizagem.

Assim, é fundamental nos articularmos nessa rede, constituída de espaços de aprendizagem híbridos, representados ora por situações presenciais físicas, ora por situações presenciais virtuais. 


\section{A UNISINOS}

A Universidade do Vale do Rio dos Sinos - UNISINOS é uma Universidade da Companhia de Jesus, ordem religiosa que se dedica a quatro séculos e meio a Educação dos povos, fundada por padres Jesuítas e localizada em São Leopoldo no Estado do Rio Grande do Sul, ao sul do Brasil.

Considerada uma universidade de grande porte, a UNISINOS representa um pólo de educação por toda a vida e por meio de seus projetos e programas na graduação, pós-graduação e extensão, linhas de pesquisa e de ação cultural e comunitária impulsiona:

"o desenvolvimento integral da pessoa, a partir da visão cristã do papel do ser humano no mundo e na história, bem como da integração dos processos interativos de geração, transmissão e aplicação do conhecimento numa perspectiva interdisciplinar, multidisciplinar e transdisciplinar" (Documento Missão e Perspectivas 2006-2011, 2006).

Atualmente o corpo discente é de 28 mil alunos e o corpo docente em torno de 1.000 professores (contando lato sensu).

A Missão, Visão e Credo da Unisinos constituem-se em:

- A Missão: Promover a formação integral da pessoa humana e sua capacitação ao exercício profissional, incentivando o aprendizado contínuo e a atuação solidária para o desenvolvimento da sociedade.

- A Visão: Ser referência na promoção da educação por toda a vida, estar comprometida com o desenvolvimento regional e ser impulsionada por pessoas solidárias, criativas e inovadoras.

- Credo: A Unisinos crê que o seu compromisso fundamental com a sociedade é o de promover a cultura do homem, que provém do homem e é para o homem.

\section{O PROJETO PEDAGÓGICO}

O projeto pedagógico da UNISINOS fundamenta-se nos princípios da Pedagogia Inaciana que busca a formação integral do ser humano, compreendida, em parte, 
como desenvolvimento da personalidade (espírito, inteligência, vontade e corpo). No todo, se apresenta como incremento contínuo do amor à verdade e ao bem, situados no conjunto da vida, visando a excelência humana e acadêmica. É um permanente exercício de liberdade, que possibilita educação numa ética de inclusão e solidariedade dos valores humanos. Favorece a participação na vida profissional e comunitária, manifestando intenção sincera de comprometer-se com a fé que promove a justiça.

\section{TRAJETÓRIAS DA MODALIDADE DE EAD NA UNISINOS}

\section{O princípio}

A EaD é uma área que vem se consolidando na UNISINOS, desde 1998, quando teve início à criação de um primeiro protótipo de ambiente virtual, com metodologia fundamentada na concepção interacionista/construtivista, cujo objetivo era realizar capacitação a distância em Informática na Educação e Tecnologias de Informação ${ }^{3}$. Nesse mesmo ano, o Ambiente passou a ser utilizado na UNISINOS, no Centro de Ciências Humanas, para dar suporte a cursos de extensão na área de Informática na Educação, para a disciplina de Informática na Educação II do curso de Licenciatura em Pedagogia e para a disciplina de Informática na Educação Matemática do curso de Pós-Graduação Especialização em Matemática Formação do Professor, do Centro de Ciências Exatas e Tecnológicas.

A partir dessas experiências, iniciou-se no segundo semestre do ano de 1999 o planejamento e o desenvolvimento do Ambiente Virtual de Aprendizagem - AVA UNISINOS $1.0^{4}$ vinculado ao curso de Licenciatura em Pedagogia e formalizado por meio de um Projeto de Ensino: Ambiente Virtual de Aprendizagem: uma proposta interdisciplinar. A iniciativa surgiu do interesse de três professoras ${ }^{5}$, integrantes do Núcleo de Apoio Pedagógico (NAP) ${ }^{6}$, em vivenciar um processo cooperativo interdisciplinar de construção do conhecimento por meio da metodologia de projetos de aprendizagem com o uso das TICs, no curso de Licenciatura em Pedagogia. A finalidade do AVA UNISINOS consistia em provocar a ação e a reflexão sobre a prática pedagógica, fundamentada numa concepção epistemológica interacionista/ construtivista, comprometida com um fazer docente que resgata o uso da tecnologia numa perspectiva crítico-humanizadora, no contexto da Pedagogia Inaciana.

A primeira experiência foi realizada no primeiro semestre de 2000, a partir da criação de uma comunidade envolvendo as disciplinas de Informática na Educação II, Teorias da Aprendizagem e Psicologia II, do curso de Pedagogia. No segundo semestre 
de 2000 o AVA UNISINOS foi utilizado em experiências em nível de extensão, de graduação, de pós-graduação e para apoiar processos administrativos. A primeira versão do AVA UNISINOS foi utilizada durante quatro semestres, totalizando mais de 800 usuários.

Essa vivência passou a subsidiar o trabalho de assessoria pedagógica para os professores dos diferentes Centros de Ensino, Pesquisa e Extensão com relação ao estudo e aplicação de novas metodologias na prática docente do ensino superior.

A opção por iniciar a inserção na área da EaD com o desenvolvimento de uma plataforma tecnológica se justifica no momento em que a Universidade, após analisar e avaliar diferentes tecnologias disponibilizadas no mercado, entende que a sua proposta pedagógica, a qual está alicerçada em bases teóricas suficientemente robustas para dar conta de uma proposta educacional inovadora, necessita estar subsidiando a construção tecnológica de forma que possa melhor traduzir a compreensão que a UNISINOS tem sobre como ocorre a aprendizagem a partir do uso de tecnologias digitais emergentes.

\section{O Ambiente Virtual de Aprendizagem - AVA UNISINOS}

O AVA UNISINOS é o Ambiente Virtual de Aprendizagem da UNISINOS e foi desenvolvido a partir de um Projeto Pedagógico Comunicacional - PPC que tem como pressupostos filosófico e institucional o Humanismo Social-Cristão, expresso na Pedagogia Inaciana; como pressuposto epistemológico, a concepção interacionista/ construtivista/ sistêmica; como pressupostos pedagógicos, a dialogicidade, a interdisciplinaridade e a transdisciplinaridade. Esses pressupostos orientaram tanto o desenvolvimento do ambiente quanto de metodologias propostas para o seu uso, nesse sentido, acredita-se que ele possa provocar desequilíbrios no sistema de significação dos sujeitos, provocando mudanças que são necessárias que ocorram no ensino para promover uma educação que responda aos desafios da complexidade do mundo atual.

Trata-se de um ambiente que possibilita a criação de comunidades e microcomunidades, ou seja, sub-sistemas que se inter-relacionam, e são interdependentes, formando sistemas no qual o todo é maior que a soma das partes. Isso expressa a concepção sistêmica, na qual o conhecimento é visto como um todo integrado, sendo que as propriedades fundamentais se originam das relações entre as partes, formando uma rede. Essas comunidades são formadas a partir de interesses em comum, em que o sujeito é o centro do processo de aprendizagem e em interação com os objetos de 
conhecimento e demais sujeitos constrói conhecimentos. Isso expressa a concepção interacionista-construtivista pois reconhece que sujeito e objeto de conhecimento são organismos vivos, ativos, abertos, em constante troca com o meio-ambiente através de processos interativos indissociáveis e modificadores das relações, a partir das quais os sujeitos em relação modificam-se entre si, compreendendo o conhecimento como um processo em permanente construção.

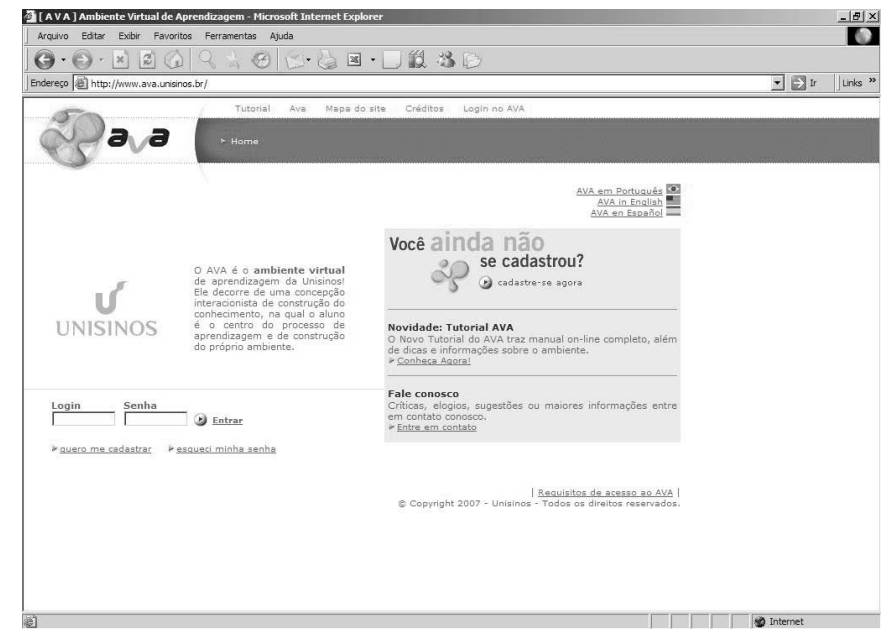

Figura 1: Abertura do AVA UNISINOS

O AVA UNISINOS comporta diferentes Atores (Administrador, Conceptor, Orientador /articulador, Aluno e Secretário) e disponibiliza diversas funcionalidades, agrupadas segundo as suas características, conforme apresentado a seguir:

Tutorial; Informações (em dois níveis: geral e da comunidade); Serviços (Agenda, Virtualteca, Glossário, Busca, FAQ, Contato, Histórico Quantitativo, Histórico Qualitativo); Comunicação (Ferramentas de Interação Assíncrona) - Mural, Fórum, Correio; Ferramentas de Interação Síncrona - Chat (Bate Papo); Webfólio Coletivo (Orientações, Avaliação, Desafios, Casos, Problemas, Projetos, Oficinas e Arquivos) e Webfólio Individual (Apresente-se, Diário e Arquivos)

\section{Metodologia}

A metodologia para utilizar o AVA UNISINOS é baseada no pressuposto da atividade cooperativa, envolve diversos espaços de interação e possibilita um processo 
de ação-reflexão continuados dos sujeitos da aprendizagem - os integrantes da comunidade. O pressuposto da atividade cooperativa inclui e incentiva a possibilidade de um trabalho interdisciplinar, pois oportuniza o desenvolvimento do pensamento e da autonomia através de trocas intelectuais, sociais, culturais e políticas e favorece a tomada de consciência.

Ametodologiaimplica num projeto comunicacional descentrado, porém mediado, em praticamente todas as funções interativas possíveis no espaço do ambiente. Desta forma procura oferecerinstrumentos efetivos para uma multiplicidade designificações que se originam nos esquemas dos sujeitos. Os professores passam a ter a função de orientadores, articuladores, problematizadores, pesquisadores e especialistas na comunidade de aprendizagem. Isto implica em participar, instigar a discussão, acompanhar e analisar a construção do conhecimento através da participação individualizada nos espaços de interação disponibilizados no ambiente.

Desta forma, segundo Schlemmer (2001), a metodologia proposta para a utilização do AVA UNISINOS está fundamentada no pressuposto epistemológico interacionista/construtivista, nos estudos de Maturana e Varela, Fagundes, Hernández e Ventura, privilegiando uma educação crítico-humanizadora. Assim, a partir dessa base conceitual desenvolve-se a metodologia de: Projetos de Aprendizagem e Identificação e Resolução de Problemas.

Essas metodologias pretendem subsidiar práticas pedagógicas inovadoras que favoreçam a constituição de comunidades virtuais de aprendizagem no paradigma da Sociedade em Rede, privilegiando uma educação crítico-humanizadora.

É possível utilizar diferentes recursos tecnológicos numa abordagem problematizadora, ou seja, a solução de situações problema, desafios, casos pode ser construída, utilizando aplicativos genéricos (processador de textos, planilha de cálculo, gerenciador de apresentação), software de autoria, softwares específicos, softwares estatísticos, WWW, HTML, Linguagens de Programação, VRML etc., dependendo do tipo de situação problema, desafio ou caso que foi proposto.

Nas propostas metodológicas abordadas acima são fundamentais a mediação pedagógica do professor e a possibilidade de interação entre os atores envolvidos. São essas premissas que fazem a diferença na qualidade de um processo educacional, no qual se prioriza a aprendizagem e a cooperação. Durante a aprendizagem, é necessário um processo de reflexão do próprio sujeito sobre sua ação. O que muitas vezes ocorre é a imposição de uma única lógica responsável por transmitir o conhecimento, ao 
invés de propiciar o desenvolvimento lógico de cada um, o qual possibilitaria ao sujeito reconstruir conceitos, estabelecer relações, entender seu próprio processo de aprendizagem, melhorando sua auto-estima. Essa preocupação é expressa por Papert, para quem "a melhor aprendizagem ocorre quando o aprendiz assume o comando”. (Papert, 1994, p.29).

Essas propostas podem ser viabilizadas através do uso de ambientes tecnológicos baseados da web que permitam a constituição de comunidades virtuais de aprendizagem. Essas comunidades podem ser formadas por orientadores/ articuladores e estudantes, caracterizando-se num espaço para partilhar recursos materiais e informações que ambos possuem. Assim, os orientadores/articuladores também aprendem, ao mesmo tempo em que os estudantes atualizam continuamente tanto seus saberes "disciplinares", ou seja, na disciplina em que são especialistas, como desenvolvem e transformam suas práticas pedagógicas.

Quanto às CVAs Schlemmer (2002) destaca que o AVA UNISINOS possibilita a constituição de CVAs a partir de afinidades de interesses, de conhecimentos, de projetos mútuos e valores de troca, que podem ser estabelecidos num processo de cooperação, formando um coletivo mais ou menos permanente dependendo dos interesses dos participantes que se organizaram em função do tempo e por meio de ferramentas oferecidas pelo AVA UNISINOS.

O reconhecimento e validação dos saberes podem ocorrer nos processos de interação, nas trocas sócio-cognitivas entre os sujeitos participantes e nas produções realizadas as quais podem ser disponibilizadas no AVA UNISINOS enquanto estão sendo desenvolvidas, garantindo a confiabilidade do processo em construção.

Ainda, as CVAs, podem ser vistas como o meio no qual os seres humanos se auto-organizam em função das interações que estão ocorrendo, pois se constituem como sistemas abertos caracterizados por fluxo e mudanças contínuas, sendo a auto-regulação uma das principais propriedades desses sistemas. A regulação é a reação do sujeito a perturbação, é uma transformação, uma modificação da ação. Ou seja, o sujeito que integra uma determinada comunidade, pode, em função de uma perturbação no seu sistema de significação, ocasionada por uma interação, regular a sua ação, ou seja, modificá-la, transformá-la, como forma de reagir a perturbação. Dessa forma, uma regulação é sempre uma construção, pois, acrescenta retroações ou trajetos em espiral a uma trajetória linear de uma ação. Assim, uma comunidade que sustente uma rede ativa de comunicação aprenderá com seus próprios erros, pois serão difundidos por toda a rede e voltarão para a sua origem ao longo de laços 
de realimentação. Devido a isso, a comunidade tem a possibilidade de corrigir seus erros, se auto-regulando e auto-organizando.

A figura abaixo apresenta a Espiral em Rede, ciclos de cooperação formando micro-comunidade (sub-sistema), fechados em si quanto ao objetivo, porém abertos e em interação com outras micro-comunidades (sub-sistemas) representando o trabalho nas CVAs no AVA UNISINOS.

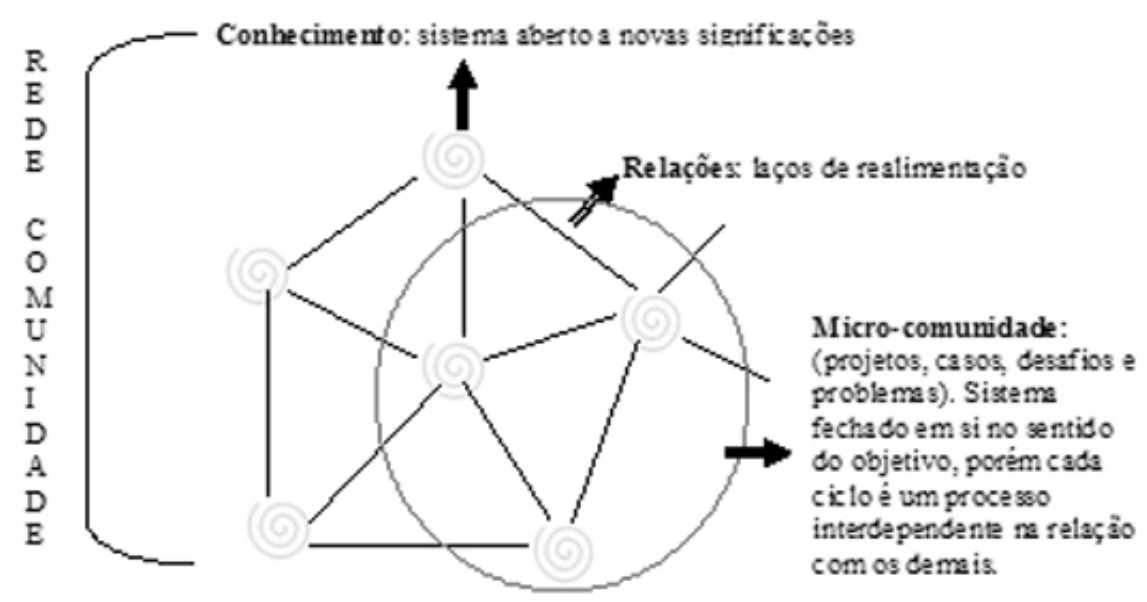

Comunidades que cooperam - rede, sistema no qual mixro-sistemas intera gem e se relac ionam.

Figura 2: Espiral em rede (Schlemmer, 2002, p. 323)

Fundamentado nos pressupostos descritos anteriormente, o desenho do AVA UNISINOS propicia e incentiva o desenvolvimento de metodologias que visam à construção de uma rede de convivência, de expressão de solidariedade na qual participam os diferentes atores (aluno, secretário, orientador/articulador, conceptor e administrador). Trata-se de descobrirmos novas formas de vivermos juntos nas dimensões simbólicas, funcionais e cognitivas, sustentadas por relações de autonomia e cooperação. A figura a seguir representa a espiral do conhecimento, na qual a aprendizagem se dá num sistema aberto e contínuo ao desenvolvimento de estruturações superiores, originadas a partir das descobertas e possibilidades surgidas no processo de interações ocorrido entre os diferentes níveis de atores. Procura resumir a idéia de uma comunidade em desenvolvimento espiral, voltada para a abertura de possíveis e a novidade? 


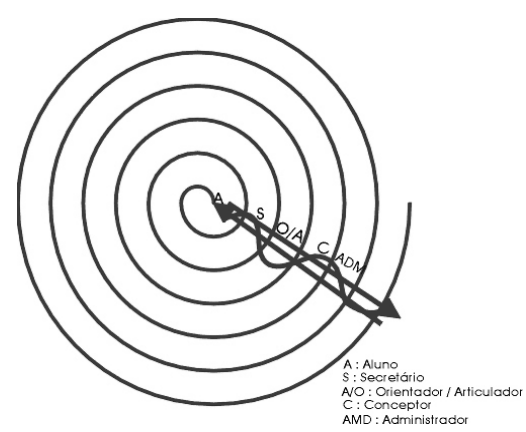

Figura 3: Espiral do conhecimento (Schlemmer et al, 2001; Schlemmer, 2002, p. 300)

Nesse sentido, a metodologia para utilização do AVA UNISINOS é baseada no pressuposto da atividade cooperativa, que possibilita um processo de açãoreflexão continuados dos sujeitos da aprendizagem. Inclui e incentiva o trabalho interdisciplinar e transdisciplinar, oportunizando o desenvolvimento do pensamento e da autonomia por meio de trocas intelectuais, sociais, culturais e políticas, efavorece a tomada de consciência da aprendizagem. Implica, ainda, um projeto comunicacional descentrado e mediado, em praticamente todas as funções interativas possíveis no espaço do ambiente. Os professores além de serem especialistas, têm a função de orientador, de articulador e de problematizador. Isso implica participação, fomento à discussão, acompanhamento e análise da construção do conhecimento por meio da participação coletiva e individualizada (Schlemmer, 2001; 2002).

Dessa forma, as possibilidades existentes no AVA UNISINOS provocam um repensar das práticas pedagógicas atuais e incentiva o desenvolvimento de práticas pedagógicas inovadora. Entre elas podemos citar, a metodologia de Projetos de Aprendizagem e Identificação e Resolução de Problemas.

\section{Avaliação}

Nessas propostas de trabalho, a avaliação é da aprendizagem, sendo formativa, continuada e realizada ao longo do processo através da participação partilhada entre os sujeitos integrantes de uma comunidade. Assim sendo, a comunidade passa a ter os seus princípios particulares de avaliação, pois envolve a definição de formas, instrumentosecritériosdeavaliação.Essaavaliaçãopodeserrealizadaindividualmente e/ou de forma cooperativa. Desenvolvendo-se a partir das expectativas iniciais dos participantes, sendo oportunizada através das interações ocorridas entre os sujeitos 
nos diferentes espaços possibilitados pelo ambiente, percorrendo todo o processo de construção do conhecimento. A avaliação continuada viabiliza uma revisão e ou uma reconstrução do processo em andamento.

\section{Estratégia de avaliação e validação do AVA-UNISINOS}

Em função de o AVA UNISINOS constituir-se num ambiente para a introdução de uma nova base de apoio tecnológico à formação de comunidades virtuais de aprendizagem - e isso ultrapassa o terreno da modalidade de ensino e aprendizagem vigente na UNISINOS -, fez-se necessário o acompanhamento sistemático e sistêmico do que acontecia com professores, alunos e outros participantes desses grupos. Desta forma, para validar e avaliar a ferramenta e os resultados optou-se por restringir o campo de observação, num primeiro momento, aos seis projetospiloto. Ao par desse conjunto, que constituirá campo de pesquisa, outras licenças de uso poderão ser concedidas, estudando-se caso a caso, segundo as conveniências da UNISINOS, desde que se possa garantir o acompanhamento e a interação requeridos pelo referencial teórico e pela metodologia.

O processo de avaliação e validação do produto e processos inerentes ao AVA UNISINOS foi desenvolvido considerando, principalmente, a comunidade de atores diretos, o que inclui, portanto, os receptores e produtores reais do ambiente.

A validação do projeto AVA UNISINOS foi acompanhada por um módulo de aferição do valor do produto e dos processos sugeridos. O que permitiu que o resultado dos projetos técnico, pedagógico e comunicacional fossem submetidos a testes de eficácia, funcionalidade e inteligibilidade. Do ponto de vista técnico, tratase de antecipar possíveis lacunas operacionais, tanto do projeto técnico, quanto dos projetos pedagógico e comunicacional. Foram também consideradas avaliações de outros usuários da universidade: um grupo que tenha usado a primeira versão do AVA UNISINOS e outro grupo que não a tenha ainda utilizado. O método desta validação foi experimental e os dados coletados por meio de questionários, entrevistas e relatos espontâneos.

A avaliação posterior dos produtos e processos do AVA UNISINOS ocorre em dois níveis: avaliação interna e avaliação externa.

A avaliação interna conta com um módulo permanente para tal fim sendo realizada pelos diferentes atores: o administrador, o conceptor, o orientador/ articulador, o aluno e a/o secretária/o, bem como as suas interfaces em diferentes 
níveis. Um destes níveis são os processos em que está envolvido diretamente como produtor. Ao mesmo tempo, participará da avaliação por demanda (no caso, das interfaces com os outros atores).

A avaliação externa inclui a análise da produção e capacidade técnica da comunidade acadêmica, utilizando-se de diferentes meios de pesquisa e coleta de dados, conforme o interesse da instituição e do público alvo. Esta sendo permanentemente desenvolvida por meio dos instrumentos da comunidade acadêmica (artigos, workshops, demonstrações, etc.) e técnica (discussão eventual com especialistas) ou por enquetes (conforme o interesse da instituição) junto ao público alvo.

A avaliação do AVA UNISINOS é realizada continuamente por meio das possibilidades oferecidas, e efetivada no uso dos espaços, o que viabiliza uma revisão e/ou uma reconstrução, objetivando a melhoria e o aperfeiçoamento do AVA UNISINOS.

\section{Diferenciais e pontos fortes do AVA UNISINOS}

As principais diferenças que podem ser identificadas entre outros ambientes já existentes e o ambiente AVA UNISINOS são:

- Criação da ferramenta orientada por um Projeto Pedagógico Comunicacional.

- Implementação do conceito de comunidades e micro-comunidades, possibilitando o desenvolvimento de um currículo em rede, integrando diferentes áreas do conhecimento.

- Desenvolvimento de metodologias fundamentadas na concepção epistemológica interacionista/construtivista/sistêmica.

- Criação de ferramentas especificamente desenvolvidas para dar suporte as metodologias interacionista/construtivista/sistêmica (casos, desafios, problemas, projetos, oficinas).

- Criação de ferramentas especificamente desenvolvidas para dar suporte para avaliação em processo, continuada e formativa, a partir da autoria coletiva de formas, instrumentos e critérios de avaliação, permitindo o acompanhamento de toda a interação realizada por um participante de uma comunidade.

- Utilização de metadados. 
- Utilização de menus adaptativos, podendo-se apresentar novas opções e/ou suprimir outras, dependendo da comunidade ou micro-comunidade no qual o usuário se encontra.

- Criação de comunidades e micro-comunidade com recursos diferenciados e específicos de acordo com a sua natureza, permitindo a especialização do ambiente quanto à definição das ferramentas a serem utilizadas.

- Interação entre participantes de diferentes comunidades a partir de casos, desafios, problemas, projetos e oficinas.

\section{Formação Docente}

A formação docente é realizada de forma continuada, em serviço e na modalidade b-Learning, oportunizando que os docentes vivenciem as metodologias propostas no uso da ferramenta ao mesmo tempo em que colocam em prática suas aprendizagem junto aos alunos.

\section{O AVA UNISINOS hoje}

Atualmente, existe cerca de 339 CVAs no AVA UNISINOS, totalizando mais de 13.815 usuários, entre eles alunos, professores, funcionários e comunidade externa. Essas comunidades são de diferentes naturezas e apresentam características específicas de acordo com o fim a que se destinam, podendo ser classificadas em internas e externas. A maior parte é de natureza acadêmica (comunidades de disciplinas da graduação, comunidades de pós-graduação, comunidades de extensão, comunidades de grupos de pesquisa, comunidades para orientação de Trabalhos de Conclusão, comunidades de Programas de Aprendizagem das Graduações de Referência, comunidades interdisciplinares e transdisciplinares etc.) e algumas são criadas para fins administrativos/organizacionais (planejamento estratégico, organização de eventos, comunicação entre setores etc.).

Além disso, cerca de 50 instituições em diferentes países da América Latina, sendo públicas, privadas e ONGs, realizaram o download do Ambiente. Por esse motivo o AVA UNISINOS foi traduzido para o espanhol e para o inglês.

Quanto ao uso do AVA-UNISINOS, (Schlemmer, 2002) destaca que a utilização do ambiente nos processos de ensino e de aprendizagem pressupõe convencimento interno, inquietude com as atuais práticas pedagógicas, pois envolve transformação na forma de pensar e de agir no espaço educacional. 
O desenvolvimento do AVA-UNISINOS, relacionado a investigação sobre os processo de ensino e de aprendizagem desenvolvidos a partir do seu uso, bem como a proposta de formação docente e a análise do processo ocorrido, além da aplicação do AVA-UNISINOS numa proposta de inovação curricular em curso de graduação, compõe três teses de doutorado. Além disso, o AVA-UNISINOS tem sido foco de inúmeras pesquisas, resultando em mais de 60 artigos de circulação nacional e internacional, incluindo capítulos de livros.

\section{A continuidade}

Em função dos resultados obtidos, despertou interesse tanto da comunidade acadêmica interna, quanto externa e foi institucionalizado. Desenvolveu-se então em 2001, sua segunda versão, com a ampliação do grupo original integrando representantes da área da Informática e da Comunicação. No final de 2001, a Reitoria lançou um edital para o desenvolvimento de Projetos-Piloto. Foram selecionados seis projetos, propostos por professores das mais diversas áreas do conhecimento, contemplando todos os Centros de Ensino, Pesquisa e Extensão, sendo que foram privilegiados os projetos propostos interdisciplinarmente. Os integrantes dos Projetos-Piloto participaram de um programa de formação em serviço, resultando num acompanhamento do trabalho realizado.

No ano de 2002 os projetos-piloto foram desenvolvidos, acompanhados e avaliados, dando origem a inúmeras experiências com o uso do AVA-UNISINOS, fundamentalmente como "apoio" ao ensino presencial.

\section{As incertezas e indefinições políticas a desaceleração}

No entanto, no ano de 2003 a Universidade, devido a insuficiência de políticas claras sobre o futuro da EaD na Instituição, opta por restringir o uso do AVAUNISINOS somente para professores que haviam realizado o processo formativo, o que provoca um certo desconforto e indignação na comunidade de professores, uma vez que não estava previsto um projeto de continuidade da formação docente e nem de implantação de uma estrutura física de suporte e apoio tecnológico para o desenvolvimento dessa modalidade.

Em 2004 a UNISINOS opta por implantar a EaD em escala, criando o Projeto de Implantação da EAD na UNISINOS, vinculando-o, no contexto do modelo de 
Gestão Matricial adotado pela Universidade, a Unidade Acadêmica de Graduação. Essa opção teve como objetivo desenhar e operacionalizar o projeto até que se tornasse robusto o suficiente para independizar-se como uma coordenadoria, gerência ou outra unidade acadêmica, o projeto recebe o nome de Projeto SEDNA - a EAD na UNISINOS, estando o seu escopo limitado à apresentação de proposta de implantação da Educação a Distância na Universidade do Vale do Rio dos Sinos - UNISINOS e tendo como Objetivos:

- Agregar valor e inovação às ofertas da UNISINOS.

- Fortalecer a atuação da UNISINOS no raio de 100 km e ampliá-la, a médio prazo para a América Latina.

- Estabelecer políticas, diretrizes e critérios para implantação da EAD na UNISINOS.

- Atender aos pilares de sustentabilidade, de referenciabilidade e de inovação, nas ofertas.

- Apresentar diferentes opções de cursos em EAD que atendam não só aos diversos públicos da UNISINOS, mas também à sociedade em geral.

- Identificar parceiros e possíveis conveniados para oferecimento e desenvolvimento de ofertas.

- Capacitar todo o corpo docente e administrativo, relacionado com as propostas no âmbito da $\mathrm{EAD}$, no que respeita à concepção e à gestão.

O projeto tem ainda um desdobramento chamado Projeto para Inserção da UNISINOS no Sistema de Educação à Distância" que consiste em um plano de negócios cuidadosamente elaborado.

No entanto, em outubro de 2005, a UNISINOS apesar de haver investido em um programa de capacitação para 140 docentes somente 5 disciplinas de graduação, na modalidade EaD, estavam sendo ofertadas, e alguns cursos de latu-sensu elaborados, mas apenas um efetivado com uma edição, de forma que ficou evidenciado que não houve um desdobramento posterior a formação ofertada com o envolvimento desses professores no projeto, ministrando disciplinas ou propondo cursos, como era de se esperar. Algumas hipóteses podem ser lançadas no intuito de compreender a realidade estabelecida:

A formação de um núcleo de $\mathrm{EaD}$, responsável pelo desenvolvimento de produtos, com professores e carga horária especificamente dedicadas resultou na compreensão do Núcleo enquanto um "corpo fechado", com pouca relação com o restante da 
Universidade, o que conseqüentemente gerou pouco envolvimento dos colegiados e coordenadores de curso que entendiam não ser necessário o envolvimento dos cursos na apropriação efetiva dessa modalidade para que o EAD na UNISINOS acontecesse. O Núcleo era visto como algo incômodo, que demandava mais trabalho às já lotadas agendas de professores e coordenadores. Ou seja, o modelo não logrou que o $\mathrm{EaD}$ permeasse os cursos e que o corpo docente realmente se apropriasse do mesmo.

A capacitação em larga escala do corpo docente, sem diretrizes de aplicação imediata da modalidade, por esses professores, resultou inócuo e dispendioso para a Universidade. Foram capacitados mais professores do que disciplinas/atividades que poderiam ser ofertadas naquele momento. A formação do corpo docente, nos aspectos didático-pedagógicos, tecnológicos, comunicacionais e gestão, para desenvolvimento de práticas pedagógicas na modalidade a distância é fundamental para o sucesso de um projeto em EaD, trata-se de uma aprendizagem do tipo fazer e compreender, onde o nível de compreensão vai sendo ampliado, resultando numa maior significação e, portanto, apropriação, a partir da efetiva vivência e ação do docente nessa modalidade, estando tanto o acompanhamento do desenvolvimento quanto os resultados atingidos sob o foco de intensos processos reflexivos que poderão retro-alimentar tais práticas no entanto, agora num novo patamar de compreensão, podendo inclusive gerar novas práticas.

A modalidade com aplicação em escala, na UNISINOS, pode ser considerada recente, nesse sentido é fundamental o trabalho de ganho de credibilidade junto ao corpo docente e discente; por exemplo, a utilização do $\mathrm{EaD}$ como forma de extinção de antigos currículos, para buscar-se uma otimização econômica, no momento onde a modalidade ainda não é consenso, certamente é prejudicial ao necessário ganho de credibilidade da mesma, e tampouco redunda em economia para a Universidade, pois envolve a remuneração de direitos autorais aos professores, pela organização das atividades acadêmicas/disciplinas, sem possibilidade de escala.

Por último a indefinição de elementos como progressividade e priorização de implantação do $\mathrm{EaD}$, envolvendo disponibilização de infra-estrutura de apoio e suporte tecnológico, que deveriam nortear o projeto SEDNA, também contribuiu para a fragilidade na operacionalização do mesmo.

\section{O reposicionamento estratégico e a retomada do vôo}

Então, em outubro de 2005 a UNISINOS decide reposicionar a EaD claramente como uma oportunidade criando o Escritório de Gestão de Projetos em EAD da UNISINOS, cujo objetivo passa centra-se no apoio ao planejamento, 
ao desenvolvimento e a avaliação dos projetos que envolvam atividades de ensino e de aprendizagem nas modalidades b-Learning e/ou e-Learning, nas áreas de conhecimento e diferentes níveis de ensino da UNISINOS; Graduação, Educação Continuada (de acordo com o interesse) e Pós-graduação (de acordo com o interesse). Ainda atender a demandas externas da Universidade, sempre que forem pertinentes ao compromisso educacional em geral.

\section{O escopo de atuação do GEAD passa a:}

- Apoiar o planejamento de projetos de ensino e de aprendizagem nas modalidades b-Learning e/ou e-Learning, do ponto de vista de gestão e orçamento e do ponto de vista didático-pedagógico;

- Formar professores vinculados a projetos que envolvam EaD;

- Acompanhar e supervisionar o processo técnico-didático-pedagógico de desenvolvimento dos projetos, assegurando a sua qualidade de acordo com as políticas e diretrizes definidas para EaD na UNISINOS;

- Avaliar o desenvolvimento e resultados dos projetos, do ponto de vista pedagógico, de gestão e de orçamento;

- Articular ações e prospectar oportunidades de projetos em EaD em contato com as diferentes Diretorias de Unidade e coordenações de curso da UNISINOS e demais setores relacionados direta e indiretamente com a modalidade

- Realizar articulação com entidades (órgãos governamentais, não governamentais, empresas, etc.) externas relacionadas ao desenvolvimento do EaD.

- Gerenciar/indicar/organizar os recursos físicos e tecnológicos necessários para o desenvolvimento de projetos de $\mathrm{EaD}$

Observa-se, na proposta do Escritório, que o escopo é ampliado, contemplando além de ações internas, respondendo a uma demanda da Universidade, prospectar e atender à demandas externas à Universidade.

A vinculação de um espaço que congrega atendimentos internos e externos potencializa um significativo conhecimento da diversidade de modelos de gestão existentes (e em fase de implantação) o qual gera uma visão de natureza ampla sobre as possibilidades da EaD. 
O Escritório inicia o desenvolvimento da suas ações em EaD com uma estrutura bastante enxuta composta por Coordenador(a), um professor(a), como apoio pedagógico e um funcionário(a), utilizando a estrutura de apoio da Universidade para as questões relacionadas a orçamentos, infra-estrutura tecnológica e de suporte, dentre outras necessária a efetivação dos ações em EaD. Trabalha por metodologia de projetos, a partir de demandas, buscando, (preferencialmente internamente à Universidade, mas com possibilidade de busca externa), recursos necessários, organizando-os para o desenvolvimento e realização do projeto demandado.

O modelo a seguir ilustra o fluxo de atuação amplo do Escritório.

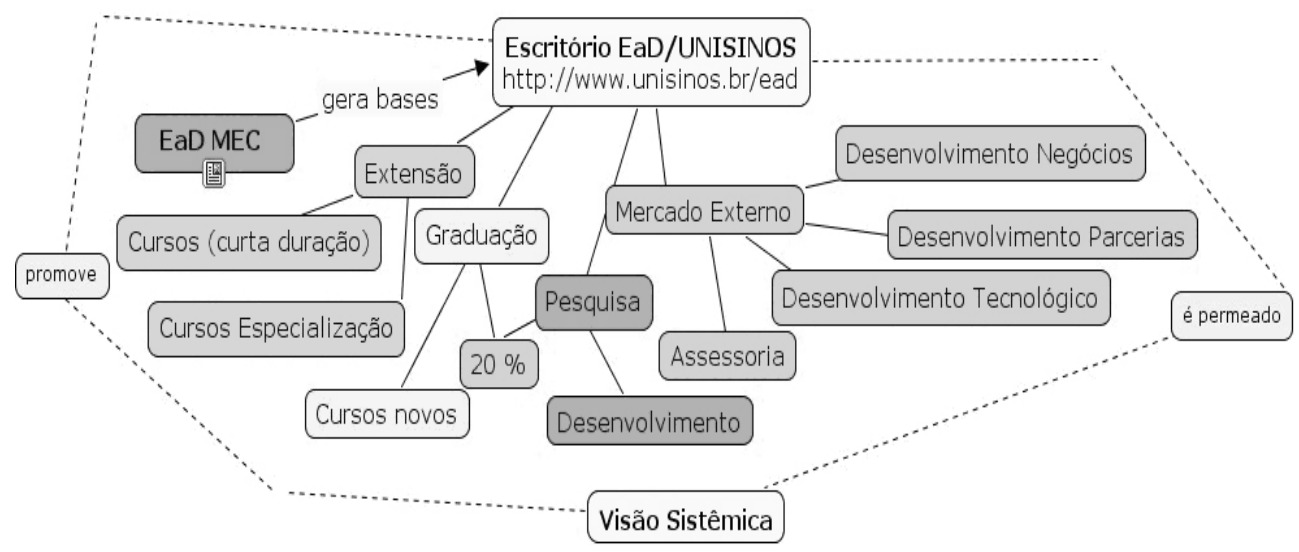

Figura 4: Fluxo atuação Gestão de Projetos em EAD - UNISINOS

É a partir dessa inter-relação que o Escritório passa a operar num âmbito macro (de gestão dos processos) e micro (de execução/acompanhamento desses mesmos processos). Ele passa a ter uma natureza ambígua que o permite pensar o próprio modelo institucional (e os diferentes modelos das outras organizações) ideal ou próximo do ideal de EaD, e o de operacionalizar todas as atividades geradas dessa modalidade, na prática, juntamente com as equipes destinadas para tal.

Com relação aos modelos de gestão tradicionais que se detêm apenas ao atendimento de demandas internas das organizações, o diferencial que se apresenta aqui, no âmbito macro, são as possibilidades de Geração Tecnológica, de novos Negócios e de parcerias que promovem a Educação a Distância, além de uma simples modalidade de educação, à captadora/captora de novas receitas. 
No que se refere ao âmbito micro, a visão sistêmica acoplada ao referencial pedagógico e à mobilidade organizacional representa o processo pelo qual as atividades em $\mathrm{EaD}$ começam, de fato, a se materializar.

Na perspectiva (sistêmica), os processos cognitivos são compreendidos como fenômenos influenciados e interferentes no uso das tecnologias, bem como, nas interações entre os sujeitos das relações de ensino e de aprendizagem e entre os sujeitos e o meio, interações que se representam (se construtivas) como perturbações.

\begin{abstract}
"Enquanto uma unidade não entrar numa interação destrutiva com seu meio, nós, observadores, necessariamente veremos que entre a estrutura do meio e a da unidade há uma compatibilidade ou comensurabilidade. Enquanto existir essa comensurabilidade, meio e unidade atuarão como fontes de perturbações mútuas e desencadearão mutuamente mudanças de estado. A esse processo continuado, demos o nome de acoplamento estrutural." (Maturana, 2002, p.112).
\end{abstract}

\title{
Atuação na Graduação
}

No âmbito da Unidade Acadêmica de Graduação com relação a oferta de cursos de graduação da Universidade, por exemplo, o escritório não cria/desenvolve atividades acadêmicas(disciplinas), para serem ministradas. Ele é demandado pelos cursos, que recebem as orientações da Unidade Acadêmica de Graduação, organiza um processo formativo para os professores responsáveis pelas atividades acadêmicas/disciplinas, escolhidas pelos colegiados, dentro da qual o professor que deverá ministrar aula no próximo semestre, já trabalha na atividade que ministrará, evitando assim a criação de uma instância fora do colegiado de curso, a EaD deve permear, pertencer aos próprios colegiados.

Assim, a Coordenação do Escritório fica responsável por dimensionar e buscar tanto os recursos humanos quanto os tecnológicos necessários para a orientação e apoio ao desenvolvimento do projeto. É importante salientar que quem organiza a atividade é o professor responsável pelo desenvolvimento da atividade acadêmica/ disciplina, sendo de responsabilidade do Escritório propiciar todas as condições necessárias a efetivação da oferta e zelar pela manutenção e ampliação da qualidade dos produtos que a Universidade oferece, inclusive acompanhando o professor durante a sua atividade docente com os alunos. 
A EaD na graduação segue as diretrizes presentes nos referênciais de qualidade do MEC e as próprias necessidades institucionais. São ofertadas 20\% da carga horária dos cursos de graduação por meio de um processo de implantação progressiva com envolvimento dos colegiados na escolha das atividades/disciplinas à serem ofertadas. A modalidade de oferta em EAD ocorre, preferencialmente, em disciplinas/atividades que simultaneamente tem possibilidade de serem ofertadas também na modalidade presencial, favorecendo a autonomia e respeitando a possibilidade escolha de professores e alunos. Busca-se, prioritariamente, a conquista de credibilidade para a modalidade por meio de processos formativos focados na necessidade de acordo com a natureza das atividades/disciplinas, do público e seguindo a proposta pedagógica da UNISINOS. São formados somente os professores para o desenvolvimento das atividades/disciplinas que serão desenvolvidas no semestre subseqüente, evitandose assim desperdício de recursos.

\section{Atuação na Educação Continuada}

No âmbito da Unidade Acadêmica de Educação Continuada, a sistemática é a mesma descrita anteriormente com relação a Unidade Acadêmica de Graduação.

É importante ressaltar que no âmbito da pós-graduação lato sensu aguarda-se a legislação para que seja possível desenvolver ações nesse contexto.

Para as solicitações externas à Universidade, o Escritório desenvolve produtos em sua totalidade, dependendo do projeto, capacitações e consultorias também são realizadas.

\section{A Chave: Formação Docente}

A primeira etapa operacional para qualquer iniciativa em EaD, inicia com um processo de formação docente para sensibilização, conhecimento e preparação das atividades em EaD.

O fluxo do processo de formação compreende o seguinte: 


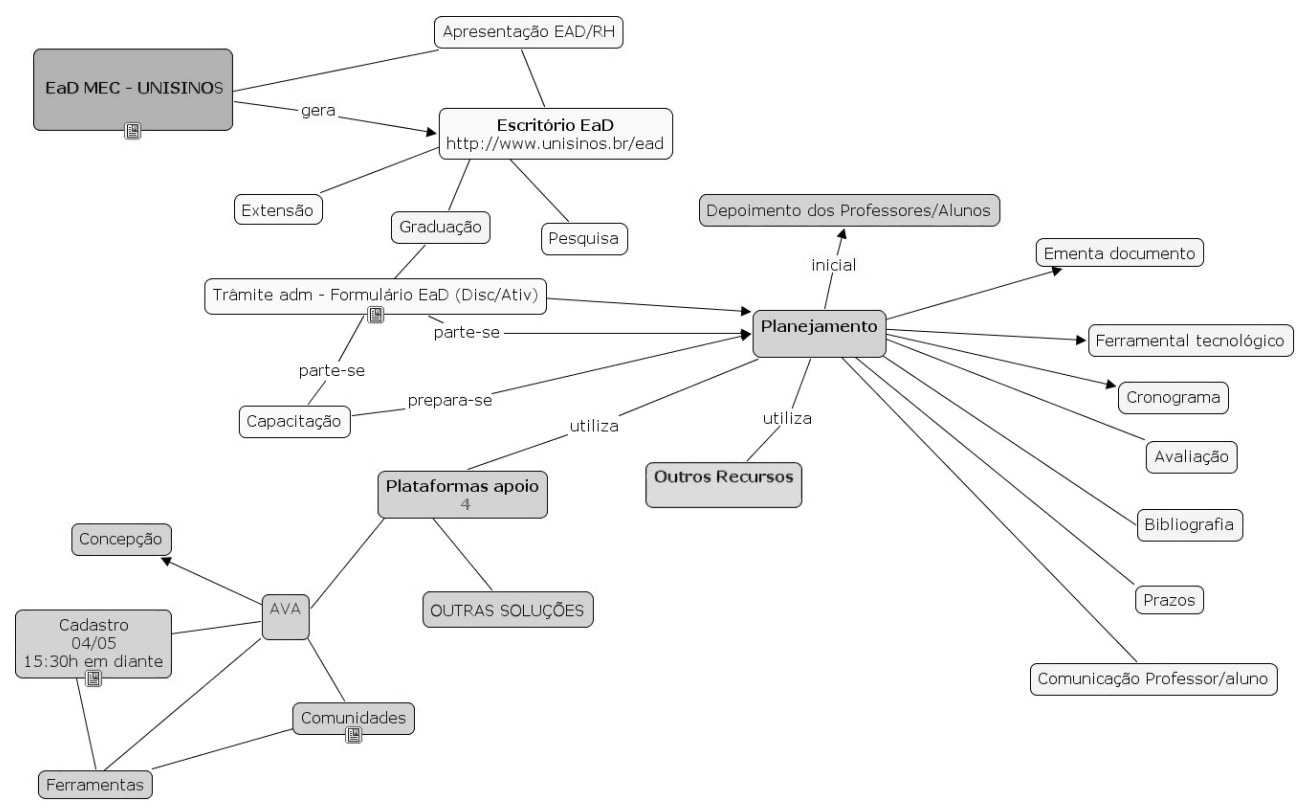

Figura 5: Fluxo do processo de formação.

\section{A Modalidade EaD na UNISINOS hoje}

A UNISINOS, em menos de um ano implantou 50 turmas diferentes de EaD totalizando mais de dois mil alunos e com uma evasão menor que a presencial, vários cursos latu-sensu bem como trabalhos desenvolvidos para clientes externos.

Sabendo que os índices de evasão tanto na Europa quanto nos Estados Unidos, atingem a ordem de $80 \%$, estamos trabalhando com o número $3 \%$ como sinal vermelho para uma intervenção junto ao nosso aluno, através do acompanhamento sistemático dos professores, orientado pelo Escritório.

Esse processo de acompanhamento, inicia-se na formação dos professores e continua durante toda a construção e execução das atividades/disciplinas de EaD. Dessa forma surge o que chamamos de compromisso orientado entre o Escritório, os professores e os alunos envolvidos no processo.

A idéia de compromisso orientado nos coloca nas proximidades daquilo que pretendemos como Instituição que aprende e coopera no que tange ao alinhamento de suas diretrizes, objetivos, necessidades e possibilidades. Com esta abordagem, 
em rede, tanto o professor quanto o aluno entram em imersão em uma idéia de interação para os processos de construção de conhecimento evitando assim a máxima behaviorista da educação mediada, simplesmente, pelo conteúdo.

A credibilidade do $\mathrm{EAD}$, enquanto modalidade de ensino, precisa ser trabalhada tanto entre os alunos quanto entre o corpo docente. A correção de percurso, na implantação do EaD, na UNISINOS, só foi possível porque ela se reconhece enquanto uma instituição que analisa, reflete, aprende e se fortaleceu, reafirmando a sua crença na modalidade.

\section{REFLEXÕES E CONSIDERAÇÕES EM PROCESSO}

A valorização do conhecimento se amplia e ganha espaço e importância em diferentes tipos de organizações que procuram maneiras inovadoras, flexíveis e criativas de formar pessoas, gestar processos e pensar a organização na sua relação com o mundo. Para muitas organizações transformar a informação em conhecimento parece ser a chave para enfrentar os desafios de forma que possam continuar a aprender, a se desenvolver, a crescer. As organizações estão buscando modificar posições conservadoras, transformando-se, para que a inovação possa emergir e assegurar a sua sobrevivência no mercado. Projetar as experiências e certezas, verdades para os desafios e problemas da atualidade, resulta numa prática equivocada, cada vez menos eficaz. A realidade atual é caracterizada por um ritmo de mudanças aceleradas e que tem pouca ou nenhuma relação com situações anteriores.

Nesse contexto, entendemos que as Tecnologias Digitais Emergentes - TDEs por si só não constituem inovação, entretanto, muito mais do que simples extensoras da mente humana, ampliadoras das formas de comunicação, facilitadoras no acesso a informação e apoio no desenvolvimento de diferentes tarefas no dia-a-dia dos sujeitos, representam uma possibilidade efetiva para o surgimento de novas compreensões com relação a conceitos como: tempo, espaço, presença, distância, interação, informação, conhecimento, provocando processos de desequilíbrio no sistema de significação do sujeito, impulsionando o rompimento de paradigmas, e modificando a forma de desenvolver determinados processos.

Essa compreensão das TDEs tem povoado a mente dos sujeitos que se apropriam delas, utilizando-as de forma crítica, refletindo sobre o que elas representam no contexto do desenvolvimento humano, das organizações e das sociedades, deslocando a compreensão da tecnologia como inovação, para compreendê-la como propulsora do surgimento de inovações. 
Entretanto, à medida que as inovações começam a se mostrar presentes nas organizações muitas vezes são abafadas, pois as organizações começam a sentir dificuldades para se adaptar às novas exigências, devido a sua estrutura burocrática e não conseguem dar lugar, abrir espaço, saber o que fazer ou onde colocar o novo. A metáfora da máquina versus seres vivos, apresentada por Capra (2002), nos ajuda a compreender essa problemática, pois segundo ele muitos administradores ainda enxergam as organizações como máquinas queprecisam decomandosedemanutenção a todo o momento, quando na verdade as organizações deveriam ser compreendidas como um sistema vivo que trabalha com pessoas que tem características próprias como flexibilidade, potencial criativo e capacidade de aprendizado.

É importante lembrar que a aprendizagem é infinita e o conhecimento ilimitado. Ter como princípio trocar informações, compartilhar conhecimentos e idéias com outros sujeitos de diferentes áreas e domínio do conhecimento humano, em diferentes funções, aceitar a contradição, o questionamento, saber escutar e expor seu ponto de vista sem ser demasiadamente apegado às suas verdades e suficientemente aberto ao diferente, valorizando o conhecimento de outros sujeitos e refletindo sobre o resultados das interações. Esse movimento, que reside em aceitar a diversidade, pode provocar a novidade, a inovação, a criatividade. Entretanto, nem sempre estamos abertos a compartilhar as nossas dúvidas, é muito mais confortável falar das nossas certezas, e de preferência para quem pensa de forma semelhante a nós, assim, seremos aceitos e valorizados, e isso traz segurança, reforça a certeza e desencadeia o sentimento de eficiência. A crítica representa uma forma de ver e pensar diferente da inicialmente exposta, não existe a resposta certa ou uma única forma de resolver um problema, até porque os desafios que encontramos na atualidade são altamente complexos, quase impossíveis de terem uma única solução e que um único sujeito possa solucioná-los. O que precisamos é fazer com que todos contribuam para que possamos ter várias possíveis respostas a fim de propiciar uma solução ótima que pode consistir da combinação de partes e relações entre as diferentes contribuições.

Existem tecnologias que são mais propícias para a troca de informações ${ }^{8}$, outras são mais adequadas ao compartilhamento de conhecimentos ${ }^{9}$, idéias e experiências e outras ainda para propiciar construção colaborativa e cooperativa ${ }^{10}$. Existem também ferramentas baseadas em mapas mentais, mapas conceituais, que se constitui num recurso para auxiliar o sujeito na organização da sua aprendizagem, do seu conhecimento. Esses podem servir também para auxiliar na identificação de sujeitos que aparentemente teriam a informação necessária num determinado contexto. Essas tecnologias se combinadas com momentos presenciais físicos de interação face-a-face, podem potencializar tanto os processos de ensino e de aprendizagem quanto os processos de gestão. É preciso lembrar que nos comunicamos 
e interagimos principalmente pela oralidade, e que em muitas dessas ferramentas, a forma de comunicação e interação predominante é a escrita, o que pode resultar em limitações para expressar idéias, compartilhar conhecimentos, experiências, entretanto, resultar num registro escrito que pode ser constantemente revisitado e modificado ou ainda, simplesmente consultado, quando se trata de um outro sujeito, para o qual isso se traduz em informação.

\section{NOTAS}

1 Termo utilizado por Sánchez e Miranda em comunicação oral no $12^{\circ}$ Congresso Internacional de Educação a Distância, A Educação a Distância e a Integração das Américas . 2005. Florianópolis.

2 O espaço de fluxos e o tempo intemporal são as bases principais de uma nova cultura, que transcende e inclui a diversidade dos sistemas de representação historicamente transmitidos: a cultura da virtualidade real, onde o faz-de-contas vai se tornando realidade (Castells, 1999, p. 398).

3 http://www.futureworld.com.br/discip/ - O desenvolvimento tecnológico se constituiu a partir dos pressupostos teóricos da Epistemologia Genética de Jean Piaget, da Pedagogia Freiriana, da Educação Crítico-Humanizadora e dos estudos realizados por Fagundes, Hernández e Ventura, Fazenda e Lévy.

4 http://www.humanas.unisinos.br/ambiente

5 Eliane Schlemmer, da disciplina de Informática na Educação II, Marly Therezinha Mallmann e Sônia Isabel Dondonis Daudt, da disciplina de Teorias de Aprendizagem.

6 Setor responsável na Universidade, pela seleção de novos professores, bem como pelo acompanhamento didático-pedagógico da prática docente nos diferentes Centros de Ensino, Pesquisa e Extensão.

7 Ver Schlemmer, E. et al (2001). Projeto Pedagógico Comunicacional do Ambiente Virtual de Aprendizagem - AVA 2.o. São Leopoldo: Universidade do Vale do Rio dos Sinos - UNISINOS. Schlemmer, E. (2002). AVA: Um ambiente de convivência interacionista sistêmico para comunidades virtuais na cultura da aprendizagem. Porto Alegre: URFGS. Tese (Doutorado em Informática na Educação).

8 Repositórios de arquivos, bibliotecas de links, de figuras, de imagens, de som, de referências e textos, bibliotecas de objetos de aprendizagem (simulações, jogos, etc.), teleconferências

9 Ferramentas que exigem um nível maior de interação - fóruns, chats, listas de discussão, videoconferências, diários de bordo problematizados, dentre outras.

10 Ferramentas que exigem em elevado nível de interação como por exemplo, ferramentas que para apoiar o desenvolvimento de projetos, a resolução de casos, dentre outros. 


\section{REFERÊNCIAS BIBLIOGRÁFICAS}

Anuário Brasileiro Estatístico de Educação a Distância. [en línea] Disponível em http://www.abraead.com.br/ [consulta 2006, dezembro]

Britain, S.; Liber, O. (1999). A Framework for Pedagogical Evaluation of Virtual Learning Environments. Bangor: University of Wales. [en línea] Disponível em: $\quad$ http://www.jtap.ac.uk/reports/ htm/jtap-041.html [consulta: 2001, junho].

Caleffi, P.; Garrido, S. (2006). Reflexions about the Politic-Pedagogical Project for On Line Education. ICDE - CD-ROM.

Capra, F. (2002). As conexões ocultas: ciência para uma vida sustentável. São Paulo: Cultrix.

Castells, M. A. (1999). Sociedade em Rede. São Paulo: Paz e Terra.

Cunha, M. I. da. (2005). Práticas Docentes Inovadoras: uma abordagem investigativa na Universidade, in: Seminário Internacional de Práticas Docente. Chile: Anais disponíveis em CD-ROM.

Fagundes, L. da Cruz; Sato, L. S.; Maçada, D. L. (1999). Projeto? O que é? Como se faz? In Aprendizes do Futuro: as inovações começaram! Coleção Informática para a mudança na Educação. Brasília: MEC. [en línea] Disponível em: http:// mathematikos.psico.ufrgs.br/textos. html [consulta: 2000, maio].

Garrido, S.; Schlemmer, E. (2006). Reflexões sobre o Projeto Político-Pedagógico para Educação a Distância (on line). Seminário Nacional de EaD da ABED. [en línea] Disponível em: http://www. abed.org.br/seminario2006/pdf/tc073. pdf [consulta 2006, dezembro]

Habermas, J. (1987). Teoria de la Accion Comunicativa: Racionalidad de la Acción y Racionalización Social. Madrid: Taurus.
Levy, P. (1993). As tecnologias da inteligência: o futuro do pensamento na era da informática. Rio de Janeiro: Editora 34.

Levy, P. (1998). Cybercultura. França: Jacob.

Maturana, H. R. (1995). Da Biologia à Psicologia. Porto Alegre: Artes Médicas.

Maturana, H. R.; Varela, F. (1995). A árvore do conhecimento. Campinas: Editorial Psy.

Maturana, H. e Varela, F. (1997). De máquinas e seres vivos: autopoiese $-a$ organização do vivo. Porto Alegre: Artes Médicas.

Maturana, H. R. (1999). Transformación en la convivência. Santiago do Chile: Dolmen Ediciones S.A.

Moraes, M. C. (2003). Educar na Biologia do Amor e da Solidariedade. Petrópolis, Rj: Vozes.

Morin, E. (1995). Introdução ao pensamento complexo. Lisboa: Instituto Piaget.

Morin, E. (1999). Para Navegar no Seculo XXI : Tecnologias do Imaginario e Cibercultura. In MARTINS, Francisco Menezes; SILVA, Juremir Machado da (Org.). Para navegar no século XXI . Porto Alegre: Sulina/Edipucrs.

Morin, E. (2002). O Método - As Idéias. Porto Alegre: SULINA.

Nonaka, I.; Takeuchi, H. (1997). Criação de conhecimento na empresa. Rio de Janeiro : Campus.

Pallof, R. M.; Pratt, K. (1998). Building Learning Communities in Cyberspace - effective strategies for the online classroom. São Francisco: Jossey-Bass Publishers.

Parrat, S; Tryphon, A. (Org.). (1998). Jean Piaget: Sobre a Pedagogia: Textos Inéditos. São Paulo: Casa do Psicólogo.

Peters, O. (2001). Didática do ensino a distância. São Leopoldo: Editora 
Unisinos.

Piaget, J. A. (1976). Equilibração das Estruturas Cognitivas. Rio de Janeiro: Zahar Editores.

Piaget, J. A. (1972). Desenvolvimento $e$ Aprendizagem. Traduzido por Paulo Francisco Slomp do original In. LAVATTELLY, C. S. e STENDLER, F. Reading in child behavior and development. New York: Hartcourt Brace Janovich.

Piaget, J. A. (1973). Estudos Sociológicos. Rio de Janeiro: Companhia Editora Forense.

Piaget, J. (1976). A Equilibração das Estruturas Cognitivas. Rio de Janeiro: Zahar Editores.

Piaget, J. (1978). A Tomada de Consciência. São Paulo: Melhoramentos.

Piaget, J. (1978). Fazer e Compreender. São Paulo: Melhoramentos.

Piaget, J. A.; García, R. (1987). Psicogênese e história das ciências. Lisboa: Publicações Dom Quixote.

Piaget, J. A. (1990). Epistemologia Genética. São Paulo: Martins Fontes.

Piaget, J. (1995). Abstração Reflexionante: relações lógico-aritméticas e ordem das relações espaciais. Porto Alegre: Artes Médicas.

Preece, J. (2005). Design de Interação: aéem da interação homem-computador. Porto Alegre: Bookman.

Primo, A. F. T.; Cassol, M. B. F. (1999). Explorando o conceito de interatividade: definições e taxionomias. Informática na Educação: Teoria e Prática, (edição de outubro), Porto Alegre: UFRGS, Faculdade de Educação, Pós-Graduação em Informática na Educação, v. 2, n. 2, 65-80.

Primo, A. F. T. (2000). Uma análise sistêmica da interação mediada por computador. Informática na Educação: Teoria e Prática, (edição de setembro), Porto Alegre: UFRGS, Faculdade de Educação, Pós-Graduação em Informática na Educação, v. 3, n. 1, 73-84.
Quinn, J. B.; Aanderson, P.; Finkelstein, S. (2000). Gerenciando o intelecto Profissional: Extraindo o Máximo dos Melhores, in: Gestão do Conhecimento: On knowledge management. Harvard Business Review.

Schlemmer, E.; Mallmann, M. T.; Daudt, S. I. D. (2000). Virtual learning environment: an interdisciplinary experience, in: WEBNET 2000 World Conference on the WWW and Internet. Webnet Journal Internet Tecnologies, Applications \& issues, 2000.

Schlemmer, E. (2000). Ambiente virtual de aprendizagem: uma experiência no ensino superior, in: $V$ Congresso IberoAmericano de Informática Educativa RIBIE 2000 (on line), Viña Del Mar. Anais disponível em CD- ROM.

Schlemmer, E. (2001). Projectos de aprendizagem basados em problemas: Uma metodologia interacionista/ construtivista para formação de comunidades em Ambientes Virtuais de Aprendizagem, in: Congreso Internacional de Informática Educativa. Madrid: UNED. Anais disponível em CDROM.

Schlemmer, E.; Fagundes, L. da C. (2001). Uma proposta para avaliação de ambientes virtuais de aprendizagem na sociedade em rede. Informática na Educação: Teoria e Prática, (edição de dezembro). Porto Alegre: UFRGS, Faculdade de Educação, Pós-Graduação em Informática na Educação, v. 4, n. 2, 25-36.

Schlemmer, E. et al. (2001). Projeto Técnico do Ambiente Virtual de Aprendizagem $A V A$ 2.o. São Leopoldo: UNISINOS.

Schlemmer, E (2001). Projeto Executivo do Ambiente Virtual de Aprendizagem $A V A$ 2.o. São Leopoldo: UNISINOS.

Schlemmer, E. (2001). Projeto Pedagógico Comunicacional do Ambiente Virtual de Aprendizagem - AVA 2.o. São Leopoldo: UNISINOS 
Schlemmer, E. (2002). AVA: Um Ambiente Virtual Baseado em Comunidades. In: XIII Simposio Brasileiro de Informatica naEducacao-SBIE 20O2. São Leopoldo: UNISINOS.

Schlemmer, E. (2002). Princípios $e$ pressupostos norteadores para a construção de uma nova graduação. São Leopoldo: UNISINOS.

Schlemmer, E. (2002). AVA: Um ambiente de convivência interacionista sistêmico para comunidades virtuais na cultura da aprendizagem. Porto Alegre: URFGS, Tese (Doutorado em Informática na
Educação) Programa de Pós Graduação em Informática na Educação, Universidade Federal do Rio Grande do Sul.

Senge, P. M. (1998). A Quinta Disciplina - Arte e Prática da Organização que Aprende. São Paulo: Editora Best Seller.

Sílvio, J. (2000). La virtualización de la Universidad ¿Cómo podemos transformar la educación superior con la tecnología? Caracas: Instituto Internacional de Educación Superior en América Latina y el Caribe (IESALC).

\section{PERFIL ACADÉMICO Y PROFESIONAL DE LAS AUTORAS}

Eliane Schlemmer, Doutora em Informática na Educação - Universidade Federal do Rio Grande do Sul - UFRGS - 2002 Mestre em Psicologia - UFRGS. Professora e Pesquisadora do Programa de Pós-Graduação em Educação da Universidade do Vale do Rio dos Sinos - UNISINOS; Coordenadora do Grupo de Pesquisa Educação Digital - GP e-du UNISINOS/CNPq (http://www.unisinos.br/pesquisa/educacaodigital/).

Conceptora do AVA-UNISINOS (http://ava.unisinos.br), do Agente Comunicativo Mariá (http://www.inf.unisinos.br/ cromoslab/maria/), do Mundo Virtual AWSINOS e do Espaço de Convivência Digital Virtual (ECoDi). Membro do Comitê Gestor da Comunidade Virtual de Aprendizagem da Rede de Instituições Católicas de Ensinos Superior - CVA-RICESU (http://www.ricesu.com.br).

E-mail: elianes@unisinos.br

Susane Martins Lopes Garrido, Doutora em Informática na Educação pela Universidade Federal do Rio Grande do Sul (2006); Mestre em Educação pela Pontifícia UniversidadeCatólica do Rio Grande do Sul(1995). AtualmenteéProfessora adjunta da Universidade do Vale do Rio dos Sinos (UNISINOS) e Coordenadora do Programa de Educação a Distância da (UNISINOS). Atua também na assessoria e consultoria a empresas que queiram implementar processos de EaD (Educação a Distância).

E-mail: susane@unisinos.br 
Paula Caleffi, Doutorado em História da América pela Universidad Complutense de Madrid, Espanha (1990). Trabalhou nos projetos: Populações nativas em espaços urbanos: Terena habitantes de Campo Grande/MS , Projeto integrado de história oral com sociedades sem escrita, Construindo um diálogo intercultural: a escuta da alteridade Guaraní. Publicou os artigos : L'A Domesticación de'l Exotic. Mondialisations Germ, Paris-França, 2005. Etno-développement durable. Mondialisations, 2005. Etnossutentabilidade. Mondialisatinos Germ, 2005. Índian. Diccionario Critico De'l Mondialisations, França, 2004.

Diretora da Unidade Acadêmica de Graduação. Gabinete Direção da Graduação E-mail:paulac@unisinos.br

DIRECCIÓN DE LAS AUTORAS

Universidade do Vale do Rio dos Sinos

Unidade de Graduação

Unidade Acadêmica de Graduação.

Av. Unisinos, 950 Centro

93022000-Sao Leopoldo, RS - Brasil - Caixa-Postal: 275

Fecha de recepción del artículo: 05/01/07

Fecha de aceptación del artículo: 02/03/07 